\title{
Extraction of Co-Products from Biomass: Example of Thermal Degradation of Silymarin Compounds in Subcritical Water
}

\author{
Lijun Duan • Sunny N. Wallace • Abigail Engelberth • \\ Justin K. Lovelady • Edgar C. Clausen • Jerry W. King • \\ Danielle Julie Carrier
}

(C) Humana Press 2009

\section{Erratum to: Appl Biochem Biotechnol \\ DOI 10.1007/s12010-009-8594-z}

This article was intended for publication in the proceedings of Biotechnology for Fuels and Chemicals: The Thirtieth Symposium, which comprised volumes 153-156. An error of classification during the peer review process prevented its inclusion in those special issues.

The online version of the original article can be found at http://dx.doi.org/10.1007/s12010-009-8594-z

L. Duan · S. N. Wallace · A. Engelberth · J. K. Lovelady • E. C. Clausen · J. W. King

Ralph E. Martin Department of Chemical Engineering, University of Arkansas,

3202 Bell Engineering Center, Fayetteville, AR 72701, USA

D. J. Carrier $(\triangle)$

Department of Biological and Agricultural Engineering, University of Arkansas,

203 Engineering Hall, Fayetteville 72701, USA

e-mail: carrier@uark.edu 